http://jmscr.igmpublication.org/home/ ISSN (e)-2347-176x ISSN (p) 2455-0450

crossref DOI: https://dx.doi.org/10.18535/jmscr/v8i1.07

Journal Of Medical Science And Clinical Research

IGM Publication

An official Publication of IGM Publication

\title{
Assessment of Carotid Intima Media Thickening In Patients with Type II Diabetes and with its Microvascular Complications
}

\author{
Authors \\ Dr R.Venkatesh ${ }^{1 *}$, Dr K. Nagarajan ${ }^{2}$, Dr P. Anand ${ }^{3}$ \\ ${ }^{1}$ Postgraduate Department of General Medicine, ${ }^{2}$ Professor and Chief Department of General Medicine, ${ }^{3}$ Assistant \\ Professor Department of General Medicine (Sri Manakula Vinayagar Medical College and Hospital) \\ *Corresponding Author
}

Dr R.Venkatesh

\begin{abstract}
Introduction: Our aim of the study is to evaluate the relationships between parameters of carotid artery intima media thickness (CIMT) and the future occurrence of microvascular complications in individuals with type 2 diabetes and pre-diabetes patients. Patients with type-2 diabetes mellitus have increased carotid intima media thickness and they are higher risk for generalized atherosclerosis.The present study was carried out to study the correlation between carotid artery intima media thickness (CIMT) with the microvascular complication of Type 2 diabetes mellitus patients. ${ }^{l}$ Carotid intima media thickness (CIMT) is used commonly as a non-invasive test for the assessment of early occurrence of microvascular complications. The objective of this study was to find out the association of increased CIMT in patients with microvascular complications of type 2 diabetes and pre-diabetes patients and to correlate CIMT with various parameters likeage,gender,HbAlc,BMI,smoking,alcohol and duration of Type 2 diabetes mellitus. Present study was undertaken to assess the carotid intima media thickening in type 2 diabetes patients and also with microvascular complications such as diabetic retinopathy, diabetic nephropathy, diabetic neuropathy. ${ }^{2}$

Objective: To study the association of carotid artery intima media thickness(CIMT) in type 2 diabetes mellitus and pre-diabetes patients and also to find the association of increased CIMT in patients with microvascular complications of type 2 diabetes and pre diabetes patients admitted in Sri Manakula Vinayagar Medical College and Hospital(SMVMCH).

Methodology: We conducted a cross sectional study among patients who were diagnosed as type 2 diabetes mellitus as per WHO criteria. The criteria used for the diagnosis of diabetes was fasting plasma glucose $\geq 126 \mathrm{mg} /$ dl or a 2 hour postprandial/OGTT plasma glucose $\geq 200 \mathrm{mg} / \mathrm{dl}$ or symptoms of hyperglycemia and random plasma glucose $\geq 200 \mathrm{mg} / \mathrm{dl}$. Patient with Type 1 Diabetes Mellitus, secondary diabetes, chronic renal failure, congestive cardiac failure were excluded from the study.

Results: Based on this study, totally 51 patients were studied and result shows that association between mean carotid intima media thickness (CIMT)with diabetic nephropathy shows that patient with increased CIMT in macroalbuminuria groups is $80 \%$ and microalbuminuria is $53.5 \%$ but P value was not statistically significant. Then association of CIMT with diabetic neuropathy shows that CIMT increased in $78.6 \%$ of mild neuropathic changes and $100 \%$ of severe neuropathic changes and it shows there was a statistically significant $P$ value $(P=<0.001)$ in this group. Finally association of CIMT with diabetic retinopathy shows that there was statistically significant $P$ value $(P$ $=<0.001$ ).

Conclusion: From this study, result shows that association of mean carotid intima media thickness (CIMT) is statistically significant with diabetic neuropathy and diabetic retinopathy changes but not statistically significant with diabetic nephropathy changes.

Keywords: carotid doppler, CIMT, diabetic mellitus, microvascular complications.
\end{abstract}




\section{Introduction}

Type 2 diabetes mellitus is a rapidly increasing chronic health disease and the accompanying long-term microvascular and macrovascular complications cause significant morbidity and mortality in patients with diabetes. The onset and progression of atherosclerosis are much more rapid in patients with diabetes than in those without diabetes. Strict glycemic control, weight loss, the improvement of insulin resistance, and the avoidance of alcohol, smoking contribute to the prevention of atherosclerosis in patients with diabetes. $^{2}$

Vascular complications due to atherosclerosis are a major cause of morbidity and mortality in type 2 diabetic patients and is more common in India where the number of diabetics is increasing in our country. Atherosclerosis is the major risk factor is quicker in diabetes mellitus. It has been proposed by the atherosclerotic risk project that the atherosclerotic process occurs at the same time in carotid, coronary and cerebral arteries. The intima media thickness of the carotid artery (CIMT) can be measured with a high degree of accuracy and reproducibility by $\mathrm{B}$ mode ultrasonography which provides a reliable and valid estimate of the arterial wall thickness and the various noninvasive imaging methods available, arterial intima media thickness measurement obtained by $\mathrm{B}$ mode ultrasound. ${ }^{1}$ It is currently recommended by the American Heart Association as being relatively safe, noninvasive and inexpensive method of assessing subclinical atherosclerosis and being an self-determining interpreter of atherosclerotic events and microvascular complications. Carotid intima media thicknessis related to cardiovascular risk factors and diseases and its measurement by means of ultrasound makes it possible to detect thickening in the initial phases of atherosclerosis and the objective of our study is to compare the mean carotid IMT in prediabetes and diabetes patients and also with complications of diabetes to analyze the increase in carotid IMT with increasing complications. ${ }^{3}$
This study also helps to assess the carotid intima media thickening in patients with microvascular complications of type 2 diabetes mellitus such as diabetic retinopathy, diabetic nephropathy, diabetic neuropathy.

\section{Materials and Methods \\ Study area and design}

This study was done at Sri Manakula Vinayagar Medical College and Hospital from May2018 to December 2018 for a period of eight months. Sri manakula vinayagar medical college is a tertiary care hospital located at madagadipet, Puducherry. The study design employed was a cross sectional study.

\section{Study Participants}

Sample size was calculated to be 51 using software Open Epi version 3.0 taking mean carotid intimal thickness as 0.98(0.27) from previous studies, relative precision of $7.5 \%$ and confidence interval of $95 \%$. Since it's a hospital based study we included all patients who is getting admitted as type 2 diabetes mellitus in general medicine and allied specialties ward for period of 8 months (May 18 to December 18) was considered as study sample size calculated to be more than 51.

Patients included were all cases of prediabetes and type 2 diabetes mellitus patients attending general medicine OPD and In-patients were randomly selected with age more than 18 years based on WHO criteria. We excluded patients with Type 1 Diabetes Mellitus, Secondary diabetes (Drug induced, endocrine disorder, cancer, chronic pancreatitis), Chronicrenal failure, Systemic Hypertension, Congestive cardiac failure with EF $<35 \%$ and patient on lipid lowering drugs.

\section{Methodology}

Patients was diagnosed with Type 2 Diabetes mellitus were randomly selected from the inpatients of the general medicine department. The criteria used for the diagnosis of diabetes was fasting plasma glucose $\geq 126 \mathrm{mg} / \mathrm{dl}$ or a 2 hour postprandial/OGTT plasma glucose $\geq 200 \mathrm{mg} / \mathrm{dl}$ or 
symptoms of hyperglycemia and random plasma glucose $\geq 200 \mathrm{mg} / \mathrm{dl}$. Patient with Type 1 Diabetes Mellitus, secondary diabetes, chronic renal failure, congestive cardiac failure were excluded from the study.

All patients studied underwent,

1) Detailed assessment of history with previous medical treatment history.

2) Complete general physical examination including anthropometric measurements and system examination for atherosclerotic vascular disease.

3) Peripheral neuropathy was assessed by monofilament test.

4) For diabetic retinopathy after adequate mydriasis a detailed fundus examination was done by a qualified ophthalmologist using a direct ophthalmoscope and diabetic retinopathy was graded as per the International classification of diabetic retinopathy and diabetic macularedema guidelines as follows: ${ }^{4}$

1 . No retinopathy

2. Mild non proliferative diabetic retinopathy

3. Moderate non proliferative diabetic retinopathy

4. Severe non proliferative diabetic retinopathy

5 . Early proliferative diabetic retinopathy

6 . High risk proliferative diabetic retinopathy

Then routine and special investigations including blood sugar, urine routine, $24 \mathrm{hrs}$ urinary protein, complete blood count, blood urea, serum creatinine and glycosylated hemoglobin were done. The fasting venous plasma glucose (FBS) and 2 hour post prandial venous plasma glucose (PPBS) estimation were also done. Urine albumin estimation was based on the immunoturbidity due to the reaction between albumin and anti-human albumin reagent and it was read at $340 \mathrm{~nm}$. HbA1c was estimated by column chromatography method and the patients were categorized as those having a HbA1c of less than $8 \%$ which indicates good control of diabetes and those having more than $8 \%$ which indicates poor control of diabetes. ${ }^{5}$

Carotid artery intima media thickness was measured byB mode ultrasound having an electric transducer with mid frequency of 7.5 MHz Scans were performed on both the right and left extra cranial carotid arteries by skilled personnel. The IMT values were measured in six well defined arterial segments- near wall and far wall of distal6mm of common carotid, the carotid bulb and proximal6mm of internal carotid artery of both sides. The final IMT considered was the average of the IMT values at the 12 sites examined. An upper limit of $0.7 \mathrm{~mm}$ was chosen for the present study based on epidemiological data currently available. ${ }^{6,7}$

\section{Statistical Analysis}

Data was entered into Microsoft excel data sheet and was analyzed using SPSS $22 \mathrm{~m}$ version software. Categorical data was represented in the form of Frequencies and proportions. Chi-square test was used as test of significance for qualitative data. Continuous data was represented as mean and standard deviation. $\mathrm{p}$ value (Probability that the result is true) of $<0.05$ was considered as statistically significant after assuming all the rules of statistical tests.

MS Excel and MS word was used to obtain various types of graphs such as bar diagram, Pie diagram. SPSS version 22 (IBM SPSS Statistics, Somers NY, USA) was used to analyze data.

\section{Results}

Table 1: Distribution of the Participants in Terms of Age (Years) $(\mathrm{n}=51)$

\begin{tabular}{|c|c|}
\hline \multicolumn{2}{|c|}{ Age (Years) } \\
\hline Mean (SD) & $52.14(9.85)$ \\
\hline Median (IQR) & $51(14)$ \\
\hline Range & $31-80$ \\
\hline
\end{tabular}

The variable Age (Years) was normally distributed (Shapiro-Wilk Test: $\mathrm{p}=0.924)$.

The mean (SD) of Age (Years) was 52.14 (9.85). The median (IQR) of Age (Years) was 51.00 (14.00). The Age (Years) ranged from $31-80$.

\begin{tabular}{|l|c|c|}
\hline Age & Frequency & Percentage \\
\hline$\leq 40$ Years & 5 & $9.8 \%$ \\
\hline $41-50$ Years & 18 & $35.3 \%$ \\
\hline 51-60 Years & 18 & $35.3 \%$ \\
\hline 61-70 Yearrs & 8 & $15.7 \%$ \\
\hline$>70$ Years & 2 & $3.9 \%$ \\
\hline Total & 51 & $100.0 \%$ \\
\hline
\end{tabular}


9.8\% of the participants had age40 Years, 35.3\% of the participants had Age 41-50 Years. 35.3\% of the participants had Age: 51-60 Years. 15.7\% of the participants had Age: $61-70$ Years and 3.9\% of the participants had Age: $>70$ Years.

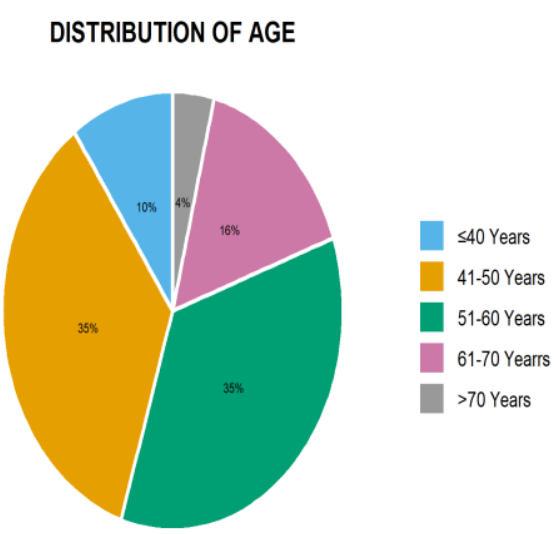

Table 2: Distribution of the Participants in Terms of Gender $(n=51)$

\begin{tabular}{|l|c|c|}
\hline Gender & Frequency & Percentage \\
\hline Male & 29 & $56.9 \%$ \\
\hline Female & 22 & $43.1 \%$ \\
\hline Total & 51 & $100.0 \%$ \\
\hline
\end{tabular}

$56.9 \%$ of the participants had Gender: Male and $43.1 \%$ of the participants had Gender: Female.

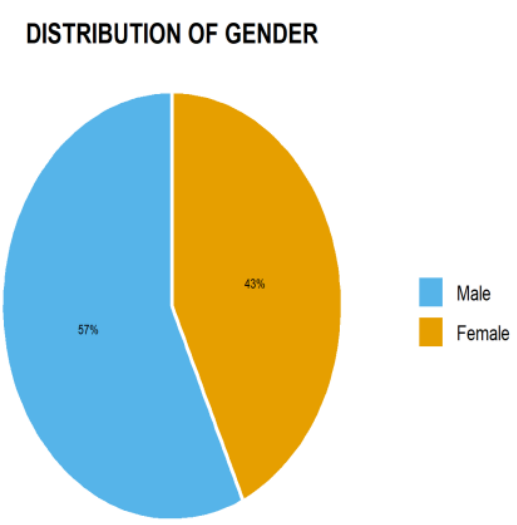

Table 3: Distribution of the Participants in Terms of Duration of Diabetes (Years) $(n=51)$

\begin{tabular}{|l|c|}
\hline \multicolumn{2}{|l|}{ Duration of Diabetes (Years) } \\
\hline Mean (SD) & $4.72(5.45)$ \\
\hline Median (IQR) & $2(6)$ \\
\hline Range & $0.5-20$ \\
\hline
\end{tabular}

The variable Duration of Diabetes (Years) was not normally distributed (Shapiro-Wilk Test: $\mathrm{p}=$ $<0.001)$.

The mean (SD) of Duration of Diabetes (Years) was 4.72 (5.45). The median (IQR) of Duration of Diabetes (Years) was 2.00 (6.00). The Duration of Diabetes (Years) ranged from 0.5 - 20.

\begin{tabular}{|l|c|c|}
\hline Duration of Diabetes & Frequency & Percentage \\
\hline Newly Diagnosed & 19 & $37.3 \%$ \\
\hline$\leq 5$ Years & 16 & $31.4 \%$ \\
\hline $6-10$ Years & 10 & $19.6 \%$ \\
\hline$>10$ Years & 6 & $11.8 \%$ \\
\hline Total & 51 & $100.0 \%$ \\
\hline
\end{tabular}

$37.3 \%$ of the participants had Duration of Diabetes: Newly Diagnosed. $31.4 \%$ of the participants had Duration of Diabetes: $=5$ Years. $19.6 \%$ of the participants had Duration of Diabetes: 6-10 Years. $11.8 \%$ of the participants had Duration of Diabetes: $>10$ Years.

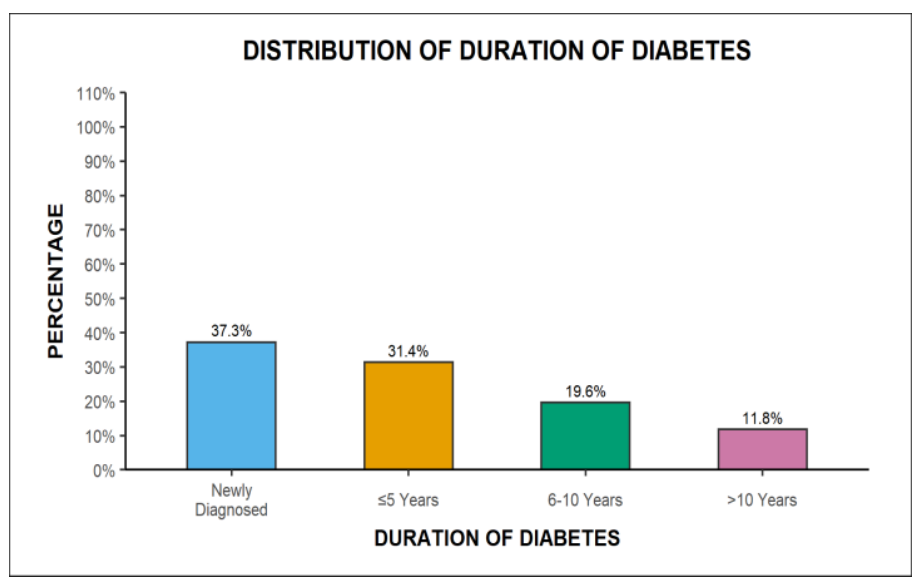

Table 4: Distribution of the Participants in Terms of Diabetes Status $(n=51)$

\begin{tabular}{|l|c|c|}
\hline Diabetes Status & Frequency & Percentage \\
\hline Diabetic & 35 & $68.6 \%$ \\
\hline Prediabetic & 16 & $31.4 \%$ \\
\hline Total & 51 & $100.0 \%$ \\
\hline
\end{tabular}

$68.6 \%$ of the participants had Diabetes Status: Diabetic. $31.4 \%$ of the participants had Diabetes Status: Prediabetic. 


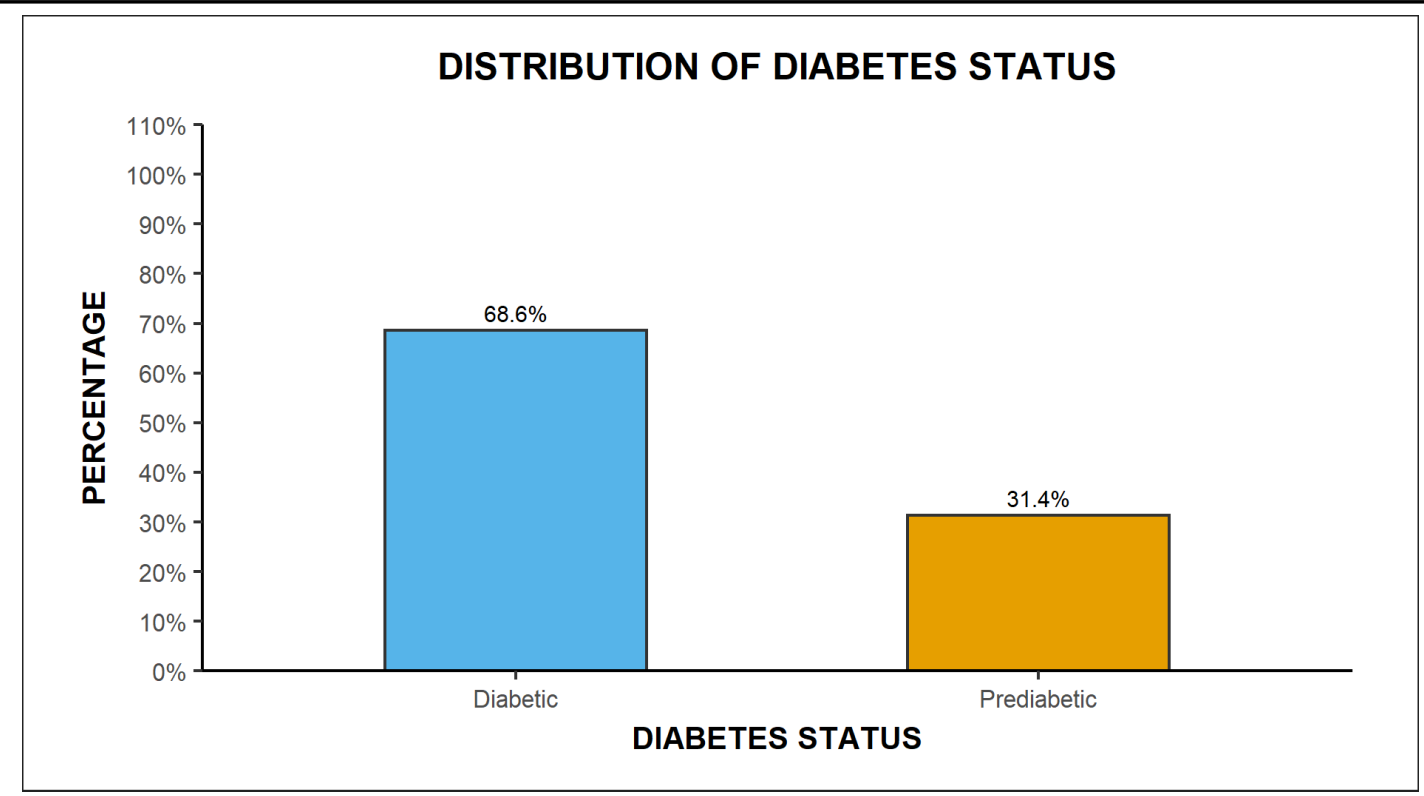

Table 5: Association Between Mean Intimal Thickness and Diabetic Nephropathy $(\mathrm{n}=51)$

\begin{tabular}{|l|c|c|c|c|c|}
\hline \multirow{2}{*}{ Diabetic Nephropathy } & \multicolumn{3}{|c|}{ Mean Intimal Thickness } & \multirow{2}{*}{ Fisher's Exact Test } \\
\cline { 2 - 4 } & $\mathbf{5 0 . 7} \mathbf{~ m m}$ & $>\mathbf{0 . 7} \mathbf{~ m m}$ & Total & \multirow{2}{*}{$\mathbf{X}^{\wedge} \mathbf{2}$} & P Value \\
\hline Absent & $3(100.0 \%)$ & $0(0.0 \%)$ & $3(100.0 \%)$ & & \\
\hline Microalbuminuria & $20(46.5 \%)$ & $23(53.5 \%)$ & $43(100.0 \%)$ & \multirow{2}{*}{4.850} & \multirow{2}{*}{0.124} \\
\hline Macroalbuminuria & $1(20.0 \%)$ & $4(80.0 \%)$ & $5(100.0 \%)$ & & \\
\hline Total & $24(47.1 \%)$ & $27(52.9 \%)$ & $51(100.0 \%)$ & & \\
\hline
\end{tabular}

Fisher's exact test was used to explore the association between 'Mean Intimal Thickness' and 'Diabetic Nephropathy' as more than $20 \%$ of the total number of cells had an expected count of less than 5.

$100.0 \%$ of the participants in the group Diabetic Nephropathy: Absent had Mean Intimal Thickness: $=0.7 \mathrm{~mm} .46 .5 \%$ of the participants in the group Diabetic Nephropathy: Absent had
Mean Intimal Thickness: $>0.7 \mathrm{~mm} .0 .0 \%$ of the participants in the group Diabetic Nephropathy: Microalbuminuria had Mean Intimal Thickness: $=0.7 \mathrm{~mm} .53 .5 \%$ of the participants in the group Diabetic Nephropathy: Microalbuminuria had Mean Intimal Thickness: $>0.7 \mathrm{~mm}$.

There was no significant difference between the various groups in terms of distribution of Mean Intimal Thickness $\left(\mathrm{X}^{\wedge} 2=4.850, \mathrm{p}=0.124\right)$.

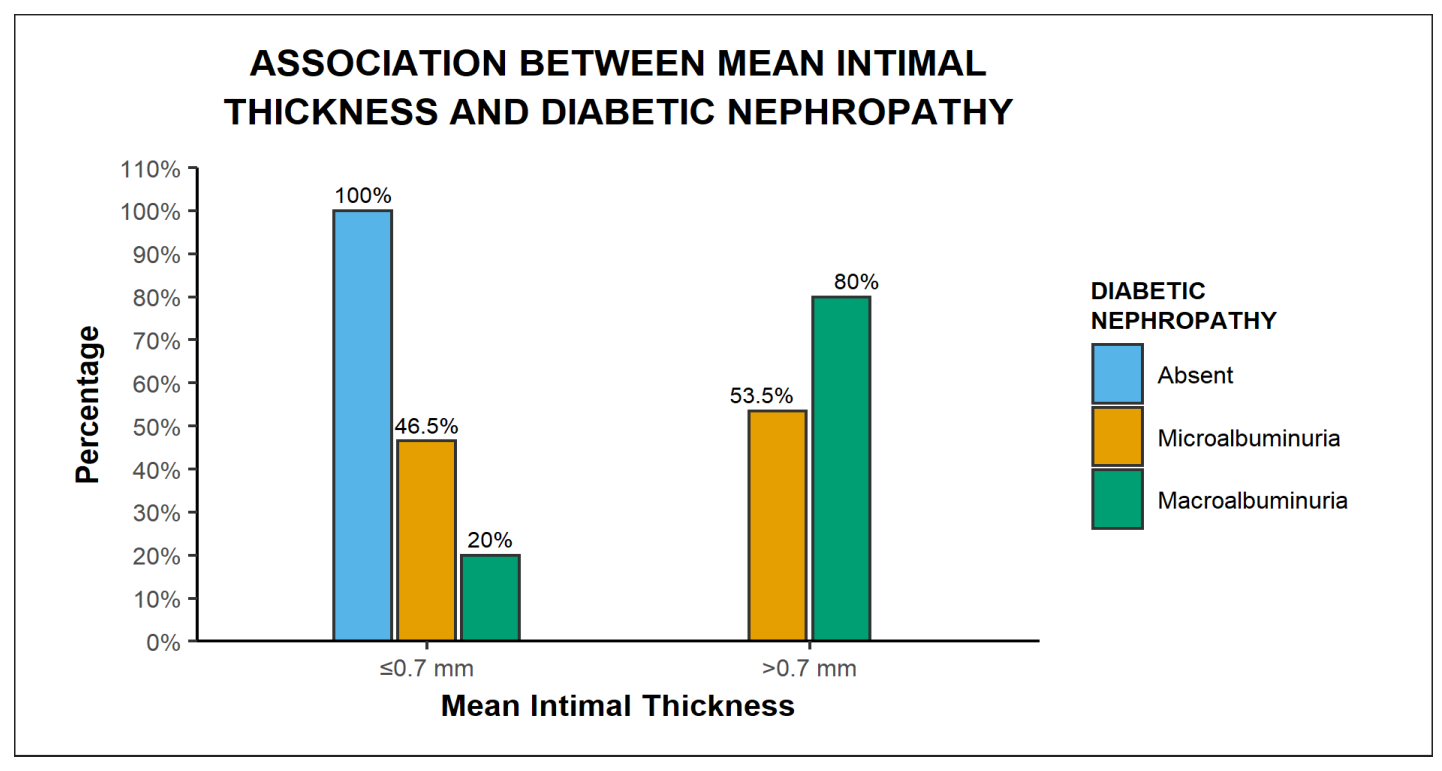


Table 6: Association between Mean Intimal Thickness and Diabetic Nephropathy in (Diabetes Status: Prediabetic) $(\mathrm{n}=16)$

\begin{tabular}{|l|c|c|c|c|c|}
\hline \multirow{2}{*}{ Diabetic Nephropathy } & \multicolumn{3}{|c|}{ Mean Intimal Thickness } & \multicolumn{2}{c|}{ Fisher's Exact Test } \\
\cline { 2 - 5 } & $\mathbf{\leq 0 . 7} \mathbf{~ m m}$ & $\mathbf{> 0 . 7} \mathbf{~ m m}$ & Total & \multirow{2}{*}{$\mathbf{X}^{\wedge} \mathbf{2}$} & P Value \\
\hline Absent & $1(100.0 \%)$ & $0(0.0 \%)$ & $1(100.0 \%)$ & & \\
Microalbuminuria & $13(86.7 \%)$ & $2(13.3 \%)$ & $15(100.0 \%)$ & \multirow{2}{*}{0.152} & \multirow{2}{*}{1.000} \\
\hline Total & $14(87.5 \%)$ & $2(12.5 \%)$ & $16(100.0 \%)$ & & \\
\hline
\end{tabular}

Fisher's exact test was used to explore the association between 'Mean Intimal Thickness' and 'Diabetic Nephropathy' as more than $20 \%$ of the total number of cells had an expected count of less than 5.

$100.0 \%$ of the participants in the group Diabetic Nephropathy: Absent had Mean Intimal Thickness: $=0.7 \mathrm{~mm} .86 .7 \%$ of the participants in the group Diabetic Nephropathy: Absent had Mean Intimal Thickness: $>0.7 \mathrm{~mm}$. $0.0 \%$ of the participants in the group Diabetic Nephropathy:
Microalbuminuria had Mean Intimal Thickness: $=0.7 \mathrm{~mm} .13 .3 \%$ of the participants in the group Diabetic Nephropathy: Microalbuminuria had Mean Intimal Thickness: $>0.7 \mathrm{~mm}$.

There was no significant difference between the various groups in terms of distribution of Mean Intimal Thickness $\left(\mathrm{X}^{\wedge} 2=0.152, \mathrm{p}=1.000\right)$.

The odds ratio $(95 \% \mathrm{CI})$ for Mean Intimal Thickness: $=0.7 \mathrm{~mm}$ in Diabetic Nephropathy: Absent as compared to Diabetic Nephropathy: Microalbuminuria was 0.56 (0.02-17.92).

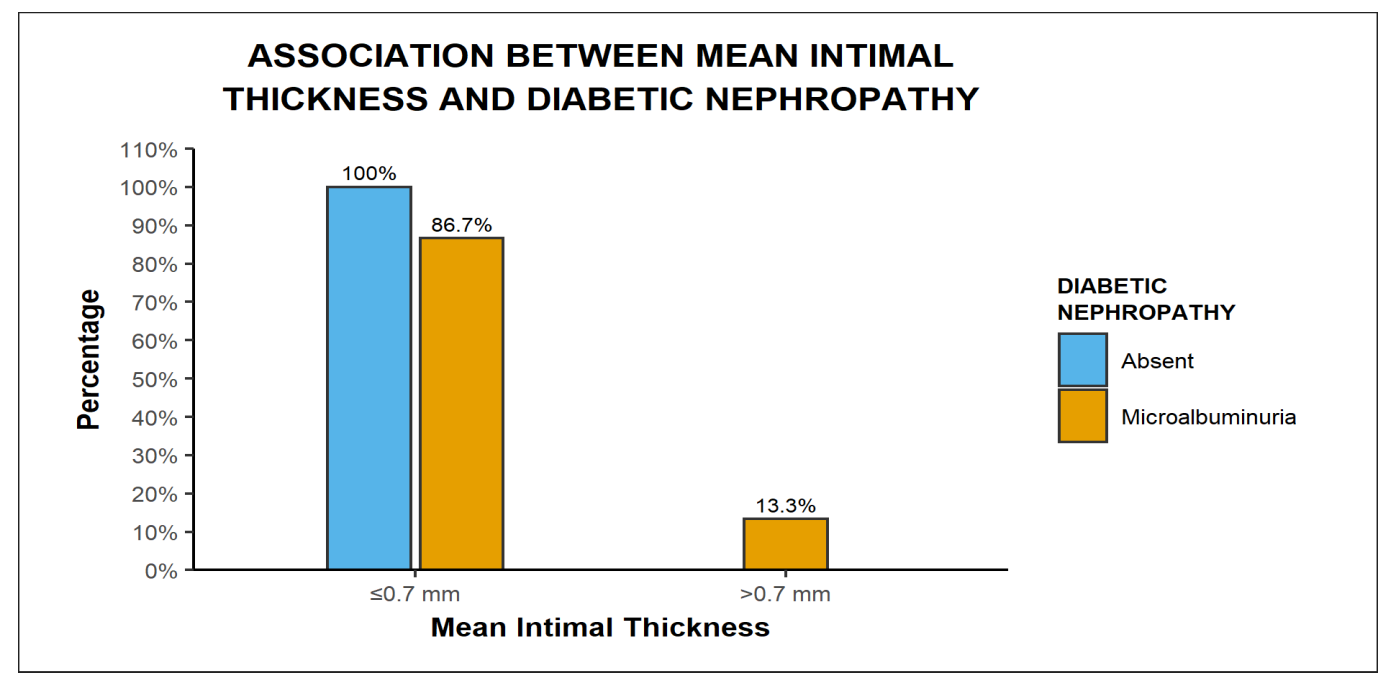

Table 7: Association between Mean Intimal Thickness and Diabetic Neuropathy $(n=51)$

\begin{tabular}{|l|c|c|c|c|c|}
\hline \multirow{2}{*}{ Diabetic Neuropathy } & \multicolumn{2}{|c|}{ Mean Intimal Thickness } & \multicolumn{2}{c|}{ Fisher's Exact Test } \\
\cline { 2 - 4 } & $\mathbf{8 0 . 7} \mathbf{~ m m}$ & $\mathbf{> 0 . 7} \mathbf{~ m m}$ & Total & \multirow{2}{*}{$\mathbf{X}^{\wedge} \mathbf{2}$} & P Value \\
\hline No Neuropathic Changes & $21(70.0 \%)$ & $9(30.0 \%)$ & $30(100.0 \%)$ & & \\
\cline { 1 - 4 } Mild Neuropathic Changes & $3(21.4 \%)$ & $11(78.6 \%)$ & $14(100.0 \%)$ & \multirow{2}{*}{16.251} & $<0.001$ \\
\hline Severe Neuropathic Changes & $0(0.0 \%)$ & $7(100.0 \%)$ & $7(100.0 \%)$ & & \\
\hline Total & $24(47.1 \%)$ & $27(52.9 \%)$ & $51(100.0 \%)$ & & \\
\hline
\end{tabular}

Fisher's exact test was used to explore the association between 'Mean Intimal Thickness' and 'Diabetic Neuropathy' as more than $20 \%$ of the total number of cells had an expected count of less than 5 .

$70.0 \%$ of the participants in the group Diabetic Neuropathy: No Neuropathic Changes had Mean
Intimal Thickness: $=0.7 \mathrm{~mm}$. $21.4 \%$ of the participants in the group Diabetic Neuropathy: No Neuropathic Changes had Mean Intimal Thickness: $>0.7 \mathrm{~mm} .30 .0 \%$ of the participants in the group Diabetic Neuropathy: Mild Neuropathic Changes had Mean Intimal Thickness: $=0.7 \mathrm{~mm}$. $78.6 \%$ of the participants in the group Diabetic 


\section{JMSCR Vol||08||Issue||01||Page 57-70||January}

Neuropathy: Mild Neuropathic Changes had Mean Intimal Thickness: $>0.7 \mathrm{~mm}$.

There was a significant difference between the various groups in terms of distribution of Mean Intimal Thickness $\left(\mathrm{X}^{\wedge} 2=16.251, \mathrm{p}=<0.001\right)$.

Participants in the group Diabetic Neuropathy: No Neuropathic Changes had the largest largest proportion of Mean Intimal Thickness: $=0.7 \mathrm{~mm}$. Participants in the group Diabetic Neuropathy: Severe Neuropathic Changes had the largest largest proportion of Mean Intimal Thickness: $>0.7 \mathrm{~mm}$.

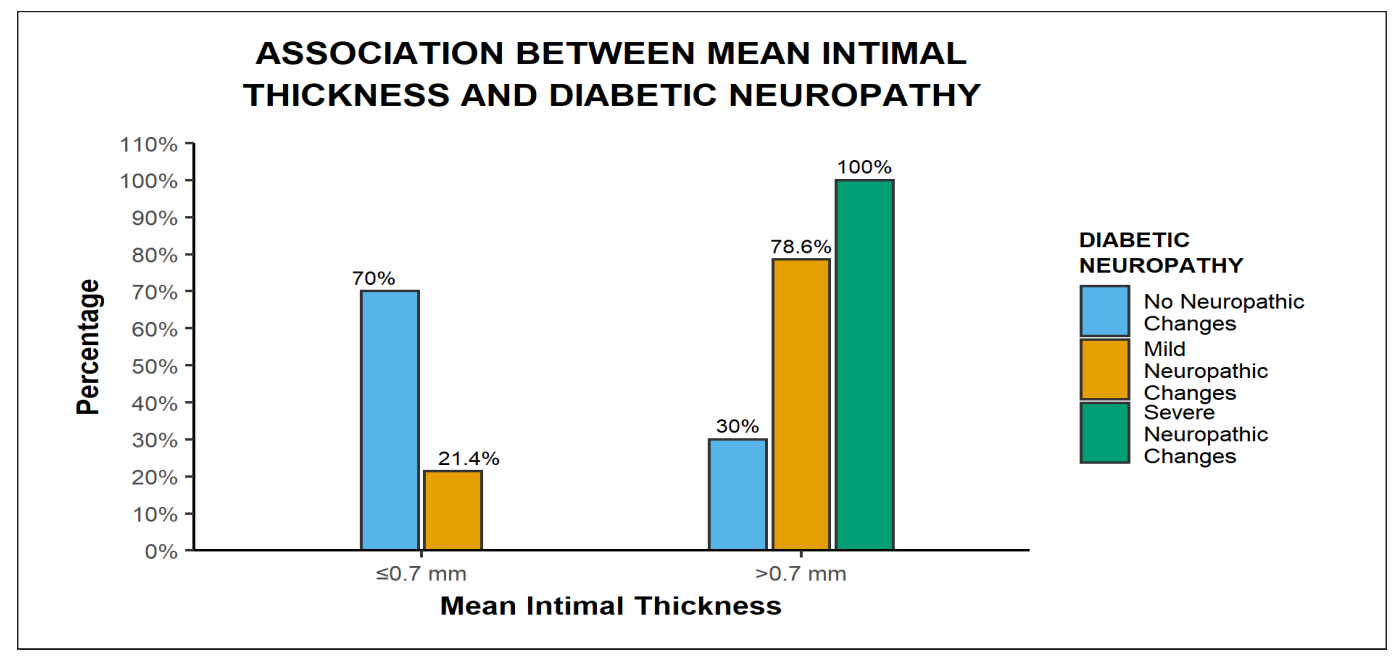

Table 8: Association between Mean Intimal Thickness and Diabetic Neuropathy in (Diabetes Status: Prediabetic) $(\mathrm{n}=16)$

\begin{tabular}{|c|c|c|c|c|c|}
\hline \multirow{2}{*}{ Diabetic Neuropathy } & \multicolumn{3}{|c|}{ Mean Intimal Thickness } & \multicolumn{2}{|c|}{ Chi-Squared Test } \\
\hline & $\leq 0.7 \mathrm{~mm}$ & $>0.7 \mathrm{~mm}$ & Total & $\mathrm{X}^{\wedge} \mathbf{2}$ & P Value \\
\hline No Neuropathic Changes & $14(87.5 \%)$ & $2(12.5 \%)$ & $16(100.0 \%)$ & \multirow{2}{*}{ 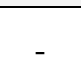 } & \multirow{2}{*}{ 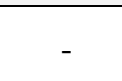 } \\
\hline Total & $14(87.5 \%)$ & $2(12.5 \%)$ & $16(100.0 \%)$ & & \\
\hline
\end{tabular}

Chi-squared test was used to explore the association between 'Mean Intimal Thickness' and 'Diabetic Neuropathy'.

$87.5 \%$ of the participants in the group Diabetic Neuropathy: No Neuropathic Changes had Mean Intimal Thickness: $=0.7 \mathrm{~mm}$.
There was no significant difference between the various groups in terms of distribution of Mean Intimal Thickness $\left(X^{\wedge} 2=-, p=-\right)$.

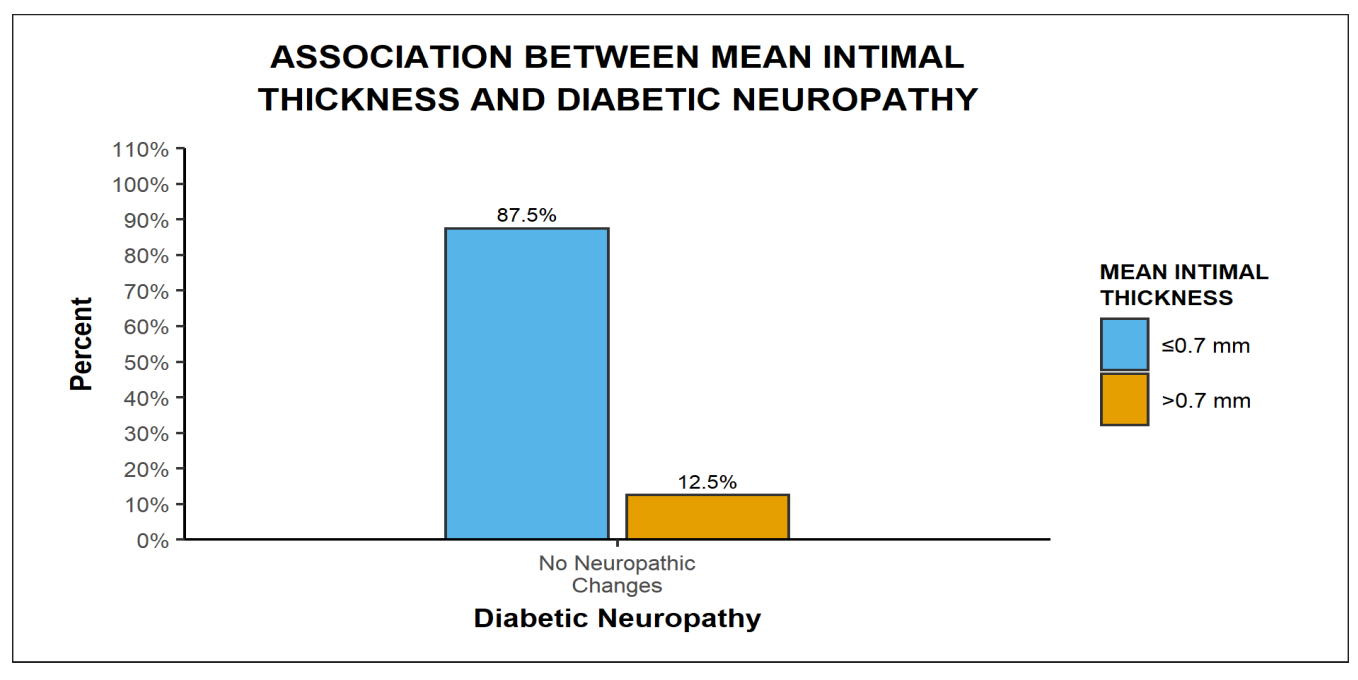


Table 9: Association between Mean Intimal Thickness and Diabetic Retinopathy $(n=51)$

\begin{tabular}{|l|c|c|c|c|c|}
\hline \multirow{2}{*}{ Diabetic Retinopathy } & \multicolumn{2}{|c|}{ Mean Intimal Thickness } & \multicolumn{2}{c|}{ Fisher's Exact Test } \\
\cline { 2 - 4 } & $\mathbf{S 0 . 7} \mathbf{~ m m}$ & $>\mathbf{0 . 7} \mathbf{~ m m}$ & Total & \multicolumn{1}{|c|}{$\mathbf{X}^{\wedge} \mathbf{2}$} & P Value \\
\hline No Retinopathy & $18(78.3 \%)$ & $5(21.7 \%)$ & $23(100.0 \%)$ & & \\
\hline Mild Non-Proliferative Retinopathy & $6(37.5 \%)$ & $10(62.5 \%)$ & $16(100.0 \%)$ & & \\
\hline Moderate Non-Proliferative Retinopathy & $0(0.0 \%)$ & $9(100.0 \%)$ & $9(100.0 \%)$ & \multirow{2}{*}{20.241} & $<0.001$ \\
\hline Severe Non-Proliferative Retinopathy & $0(0.0 \%)$ & $2(100.0 \%)$ & $2(100.0 \%)$ & & \\
\cline { 1 - 4 } Early Proliferative Retinopathy & $0(0.0 \%)$ & $1(100.0 \%)$ & $1(100.0 \%)$ & & \\
\hline Total & $24(47.1 \%)$ & $27(52.9 \%)$ & $51(100.0 \%)$ & & \\
\hline
\end{tabular}

Fisher's exact test was used to explore the association between 'Mean Intimal Thickness' and 'Diabetic Retinopathy' as more than $20 \%$ of the total number of cells had an expected count of less than 5.

$78.3 \%$ of the participants in the group Diabetic Retinopathy: No Retinopathy had Mean Intimal Thickness: $=0.7 \mathrm{~mm} .37 .5 \%$ of the participants in the group Diabetic Retinopathy: No Retinopathy had Mean Intimal Thickness: $>0.7 \mathrm{~mm} .21 .7 \%$ of the participants in the group Diabetic Retinopathy: Mild Non-Proliferative Retinopathy had Mean Intimal Thickness: $=0.7 \mathrm{~mm}$. $62.5 \%$ of the participants in the group Diabetic Retinopathy:
Mild Non-Proliferative Retinopathy had Mean Intimal Thickness: $>0.7 \mathrm{~mm}$.

There was a significant difference between the various groups in terms of distribution of Mean Intimal Thickness $\left(\mathrm{X}^{\wedge} 2=20.241, \mathrm{p}=<0.001\right)$.

Participants in the group Diabetic Retinopathy: No Retinopathy had the largest largest proportion of Mean Intimal Thickness: $=0.7 \mathrm{~mm}$. Participants in the group Diabetic Retinopathy: Moderate NonProliferative Retinopathy, Severe NonProliferative Retinopathy, Early Proliferative Retinopathy had the largest proportion of Mean Intimal Thickness: $>0.7 \mathrm{~mm}$.

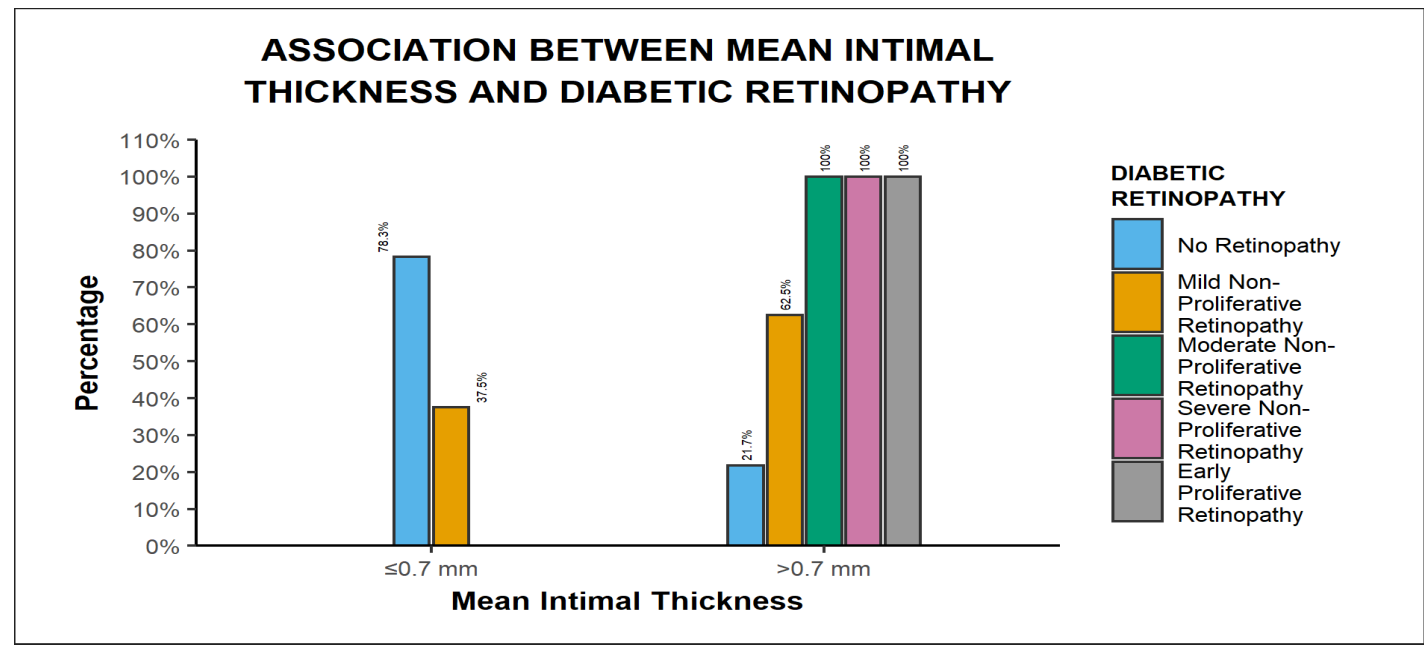

Table 10: Association between Mean Intimal Thickness and Diabetic Retinopathy in (Diabetes Status: Prediabetic) $(\mathrm{n}=16)$

\begin{tabular}{|c|c|c|c|c|c|}
\hline \multirow{2}{*}{ Diabetic Retinopathy } & \multicolumn{3}{|c|}{ Mean Intimal Thickness } & \multicolumn{2}{|c|}{ Fisher's Exact Test } \\
\hline & $\leq 0.7 \mathrm{~mm}$ & $>0.7 \mathrm{~mm}$ & Total & $X^{\wedge} 2$ & P Value \\
\hline No Retinopathy & $12(85.7 \%)$ & $2(14.3 \%)$ & $14(100.0 \%)$ & \multirow{3}{*}{0.327} & \multirow{3}{*}{1.000} \\
\hline Mild Non-Proliferative Retinopathy & $2(100.0 \%)$ & $0(0.0 \%)$ & $2(100.0 \%)$ & & \\
\hline Total & $14(87.5 \%)$ & $2(12.5 \%)$ & $16(100.0 \%)$ & & \\
\hline
\end{tabular}

Fisher's exact test was used to explore the association between 'Mean Intimal Thickness' and 'Diabetic Retinopathy' as more than $20 \%$ of the total number of cells had an expected count of less than 5. 
$85.7 \%$ of the participants in the group Diabetic Retinopathy: No Retinopathy had Mean Intimal Thickness: $=0.7 \mathrm{~mm} .100 .0 \%$ of the participants in the group Diabetic Retinopathy: No Retinopathy had Mean Intimal Thickness: $>0.7 \mathrm{~mm} .14 .3 \%$ of the participants in the group Diabetic Retinopathy: Mild Non-Proliferative Retinopathy had Mean Intimal Thickness: $=0.7 \mathrm{~mm}$. $0.0 \%$ of the participants in the group Diabetic Retinopathy:
Mild Non-Proliferative Retinopathy had Mean Intimal Thickness: $>0.7 \mathrm{~mm}$.

There was no significant difference between the various groups in terms of distribution of Mean Intimal Thickness $\left(\mathrm{X}^{\wedge} 2=0.327, \mathrm{p}=1.000\right)$.

The odds ratio $(95 \% \mathrm{CI})$ for Mean Intimal Thickness: $=0.7 \mathrm{~mm}$ in Diabetic Retinopathy: No Retinopathy as compared to Diabetic Retinopathy: Mild Non-Proliferative Retinopathy was 1 (0.0427.83).

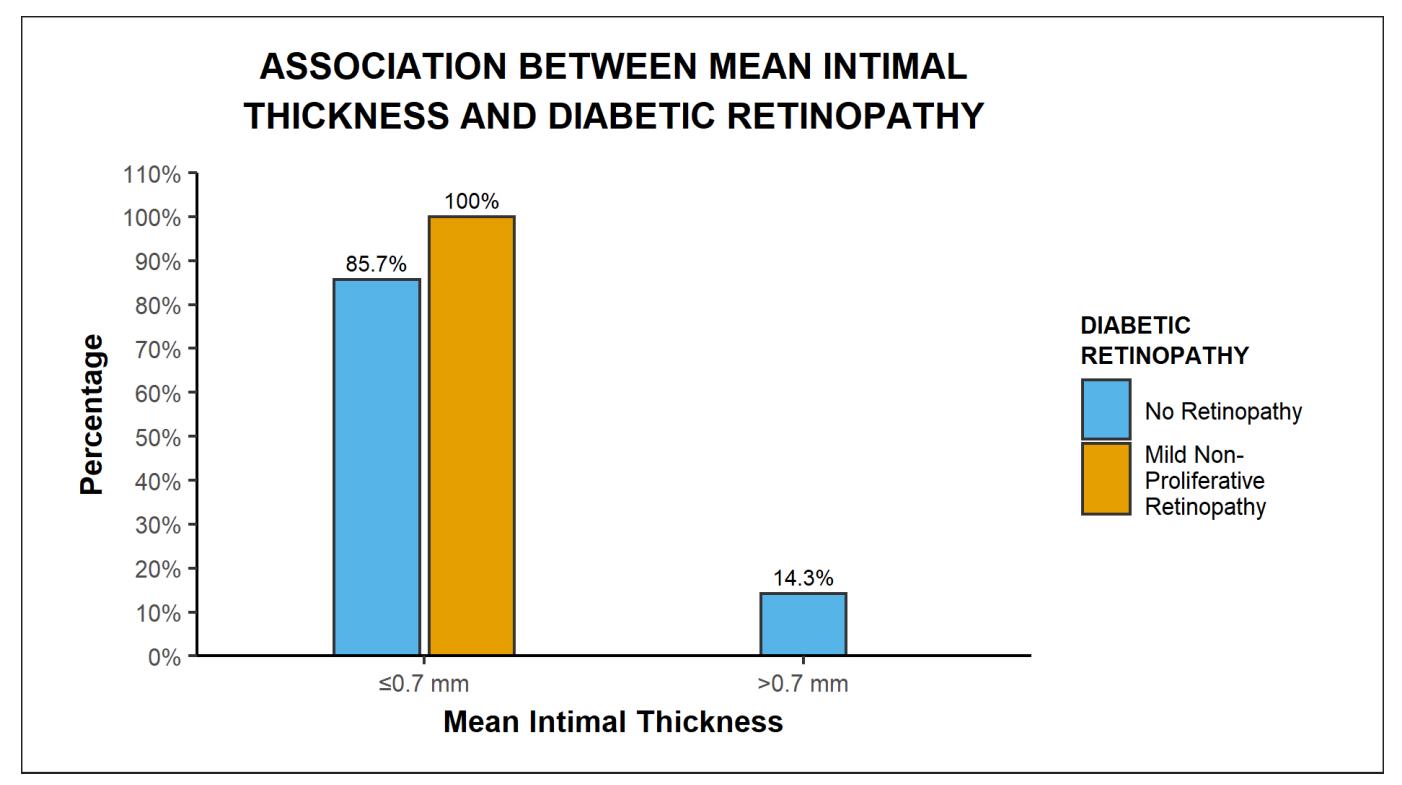

Table 11: Summary of Parameters

\begin{tabular}{|l|c|}
\hline Parameters & Mean \pm SD/N (\%) \\
\hline Age (Years) & $52.14 \pm 9.85$ \\
\hline Age & $5(9.8 \%)$ \\
\hline$\leq 40$ Years & $18(35.3 \%)$ \\
\hline $41-50$ Years & $18(35.3 \%)$ \\
\hline $51-60$ Years & $8(15.7 \%)$ \\
\hline $61-70$ Yearrs & $2(3.9 \%)$ \\
\hline$>70$ Years & $29(56.9 \%)$ \\
\hline Gender & $22(43.1 \%)$ \\
\hline Male & $4.72 \pm 5.45$ \\
\hline Female & \\
\hline Duration of Diabetes (Years) & $19(37.3 \%)$ \\
\hline Duration of Diabetes & $16(31.4 \%)$ \\
\hline Newly Diagnosed & $10(19.6 \%)$ \\
\hline$\leq 5$ Years & $6(11.8 \%)$ \\
\hline $6-10$ Years & $15(29.4 \%)$ \\
\hline$>10$ Years & $15(29.4 \%)$ \\
\hline Alcohol Use (Present) & $22.63 \pm 2.02$ \\
\hline Smoking (Present) & $207.98 \pm 86.18$ \\
\hline BMI (Kg/m2) & $298.47 \pm 110.73$ \\
\hline FBS (mg/dl) & \\
\hline PPBS (mg/dl) & \\
\hline
\end{tabular}




\begin{tabular}{|c|c|}
\hline HbA1c (\%) & $9.13 \pm 2.68$ \\
\hline \multicolumn{2}{|l|}{ Diabetes Status } \\
\hline Diabetic & $35(68.6 \%)$ \\
\hline Prediabetic & $16(31.4 \%)$ \\
\hline \multicolumn{2}{|l|}{ Diabetes Control (HbA1c) } \\
\hline Prediabetes & $16(31.4 \%)$ \\
\hline Good & $1(2.0 \%)$ \\
\hline Poor & $34(66.7 \%)$ \\
\hline Urea (mg/dl) & $29.82 \pm 8.99$ \\
\hline Creatinine (mg/dl) & $1.69 \pm 4.62$ \\
\hline 24 hrs Urine Protein (mg/day) & $131.63 \pm 96.38$ \\
\hline \multicolumn{2}{|l|}{ Urine Routine: Albumin } \\
\hline Nil & $19(37.3 \%)$ \\
\hline Trace & $20(39.2 \%)$ \\
\hline $1+$ & $6(11.8 \%)$ \\
\hline $2+$ & $5(9.8 \%)$ \\
\hline $3+$ & $1(2.0 \%)$ \\
\hline \multicolumn{2}{|l|}{ Urine Routine: Sugar } \\
\hline Nil & $10(19.6 \%)$ \\
\hline Trace & $1(2.0 \%)$ \\
\hline $1+$ & $6(11.8 \%)$ \\
\hline $2+$ & $15(29.4 \%)$ \\
\hline $3+$ & $19(37.3 \%)$ \\
\hline SGOT (IU/L) & $30.33 \pm 8.41$ \\
\hline SGPT (IU/L & $25.86 \pm 9.96$ \\
\hline Hemoglobin (gm/dl) & $11.84 \pm 1.70$ \\
\hline TLC (cells/cu.mm) & $8980.39 \pm 2041.96$ \\
\hline Platelet Count (thousand/cu.mm) & $262.49 \pm 80.25$ \\
\hline \multicolumn{2}{|l|}{ Diabetic Nephropathy } \\
\hline Absent & $3(5.9 \%)$ \\
\hline Microalbuminuria & $43(84.3 \%)$ \\
\hline Macroalbuminuria & $5(9.8 \%)$ \\
\hline \multicolumn{2}{|l|}{ Diabetic Neuropathy } \\
\hline No Neuropathic Changes & $30(58.8 \%)$ \\
\hline Mild Neuropathic Changes & $14(27.5 \%)$ \\
\hline Severe Neuropathic Changes & $7(13.7 \%)$ \\
\hline \multicolumn{2}{|l|}{ Diabetic Retinopathy } \\
\hline No Retinopathy & $23(45.1 \%)$ \\
\hline Mild Non-Proliferative Retinopathy & $16(31.4 \%)$ \\
\hline Moderate Non-Proliferative Retinopathy & $9(17.6 \%)$ \\
\hline Severe Non-Proliferative Retinopathy & $2(3.9 \%)$ \\
\hline Early Proliferative Retinopathy & $1(2.0 \%)$ \\
\hline Any Microvascular Complication (Present) & $49(96.1 \%)$ \\
\hline Mean Intimal Thickness (mm) & $0.70 \pm 0.27$ \\
\hline \multicolumn{2}{|l|}{ Mean Intimal Thickness } \\
\hline$\leq 0.7 \mathrm{~mm}$ & $24(47.1 \%)$ \\
\hline$>0.7 \mathrm{~mm}$ & $27(52.9 \%)$ \\
\hline
\end{tabular}


Table 12: Association between Mean Intimal Thickness and Parameters

\begin{tabular}{|c|c|c|c|}
\hline Parameters & $\begin{array}{c}\text { Mean Intimal } \\
\text { Thickness: } \leq 0.7 \mathrm{~mm} \\
(\mathrm{n}=\mathbf{2 4})\end{array}$ & $\begin{array}{c}\text { Mean Intimal } \\
\text { Thickness: >0.7 mm } \\
(\mathrm{n}=\mathbf{2 7}) \\
\end{array}$ & $p$ value \\
\hline Age (Years) & $47.83 \pm 8.42$ & $55.96 \pm 9.58$ & $0.002^{1}$ \\
\hline Age & & & $0.034^{2}$ \\
\hline$\leq 40$ Years & $5(100.0 \%)$ & $0(0.0 \%)$ & \\
\hline 41-50 Years & $10(55.6 \%)$ & $8(44.4 \%)$ & \\
\hline 51-60 Years & $7(38.9 \%)$ & $11(61.1 \%)$ & \\
\hline 61-70 Yearrs & $2(25.0 \%)$ & $6(75.0 \%)$ & \\
\hline$>70$ Years & $0(0.0 \%)$ & $2(100.0 \%)$ & \\
\hline Gender & & & $0.134^{3}$ \\
\hline Male & $11(37.9 \%)$ & $18(62.1 \%)$ & \\
\hline Female & $13(59.1 \%)$ & $9(40.9 \%)$ & \\
\hline Duration of Diabetes (Years) & $1.42 \pm 1.67$ & $7.65 \pm 5.97$ & $<0.001^{4}$ \\
\hline Duration of Diabetes & & & $<0.001^{2}$ \\
\hline Newly Diagnosed & $16(84.2 \%)$ & $3(15.8 \%)$ & \\
\hline$\leq 5$ Years & $7(43.8 \%)$ & $9(56.2 \%)$ & \\
\hline 6-10 Years & $1(10.0 \%)$ & $9(90.0 \%)$ & \\
\hline$>10$ Years & $0(0.0 \%)$ & $6(100.0 \%)$ & \\
\hline Alcohol Use (Present) & $4(26.7 \%)$ & $11(73.3 \%)$ & $0.060^{3}$ \\
\hline Smoking (Present) & $5(33.3 \%)$ & $10(66.7 \%)$ & $0.205^{3}$ \\
\hline BMI (Kg/m2) & $22.30 \pm 1.85$ & $22.92 \pm 2.16$ & $0.270^{1}$ \\
\hline FBS (mg/dl) & $167.79 \pm 78.03$ & $243.70 \pm 77.97$ & $0.001^{4}$ \\
\hline PPBS (mg/dl) & $256.88 \pm 106.91$ & $335.44 \pm 102.23$ & $0.012^{4}$ \\
\hline HbA1c (\%) & $7.69 \pm 2.25$ & $10.40 \pm 2.40$ & $<0.001^{4}$ \\
\hline Diabetes Status & & & $<0.001^{3}$ \\
\hline Diabetic & $10(28.6 \%)$ & $25(71.4 \%)$ & \\
\hline Prediabetic & $14(87.5 \%)$ & $2(12.5 \%)$ & \\
\hline Diabetes Control (HbA1c) & & & $<0.001^{2}$ \\
\hline Prediabetes & $14(87.5 \%)$ & $2(12.5 \%)$ & \\
\hline Good & $0(0.0 \%)$ & $1(100.0 \%)$ & \\
\hline Poor & $10(29.4 \%)$ & $24(70.6 \%)$ & \\
\hline Urea (mg/dl) & $27.12 \pm 6.86$ & $32.22 \pm 10.05$ & $0.038^{1}$ \\
\hline Creatinine $(\mathrm{mg} / \mathrm{dl})$ & $2.39 \pm 6.74$ & $1.06 \pm 0.27$ & $0.731^{4}$ \\
\hline 24 hrs Urine Protein (mg/day) & $99.50 \pm 80.46$ & $160.19 \pm 101.68$ & $0.019^{4}$ \\
\hline Urine Routine: Albumin & & & $0.531^{2}$ \\
\hline Nil & $10(52.6 \%)$ & $9(47.4 \%)$ & \\
\hline Trace & $11(55.0 \%)$ & $9(45.0 \%)$ & \\
\hline $1+$ & $2(33.3 \%)$ & $4(66.7 \%)$ & \\
\hline $2+$ & $1(20.0 \%)$ & $4(80.0 \%)$ & \\
\hline $3+$ & $0(0.0 \%)$ & $1(100.0 \%)$ & \\
\hline Urine Routine: Sugar & & & $0.008^{2}$ \\
\hline Nil & $9(90.0 \%)$ & $1(10.0 \%)$ & \\
\hline Trace & $0(0.0 \%)$ & $1(100.0 \%)$ & \\
\hline $1+$ & $2(33.3 \%)$ & $4(66.7 \%)$ & \\
\hline $2+$ & $8(53.3 \%)$ & $7(46.7 \%)$ & \\
\hline $3+$ & $5(26.3 \%)$ & $14(73.7 \%)$ & \\
\hline SGOT (IU/L) & $29.38 \pm 6.36$ & $31.19 \pm 9.92$ & $0.634^{4}$ \\
\hline SGPT (IU/L & $25.12 \pm 4.22$ & $26.52 \pm 13.19$ & $0.849^{4}$ \\
\hline Hemoglobin (gm/dl) & $12.10 \pm 1.62$ & $11.61 \pm 1.76$ & $0.273^{4}$ \\
\hline TLC (cells/cu.mm) & $8550.00 \pm 1893.47$ & $9362.96 \pm 2126.96$ & $0.155^{1}$ \\
\hline Platelet Count (thousand/cu.mm) & $275.75 \pm 75.54$ & $250.70 \pm 83.84$ & $0.180^{4}$ \\
\hline Diabetic Nephropathy & & & $0.124^{2}$ \\
\hline Absent & $3(100.0 \%)$ & $0(0.0 \%)$ & \\
\hline Microalbuminuria & $20(46.5 \%)$ & $23(53.5 \%)$ & \\
\hline Macroalbuminuria & $1(20.0 \%)$ & $4(80.0 \%)$ & \\
\hline Diabetic Neuropathy & & & $<0.001^{2}$ \\
\hline No Neuropathic Changes & $21(70.0 \%)$ & $9(30.0 \%)$ & \\
\hline Mild Neuropathic Changes & $3(21.4 \%)$ & $11(78.6 \%)$ & \\
\hline Severe Neuropathic Changes & $0(0.0 \%)$ & $7(100.0 \%)$ & \\
\hline Diabetic Retinopathy & & & $<0.001^{2}$ \\
\hline No Retinopathy & $18(78.3 \%)$ & $5(21.7 \%)$ & \\
\hline Mild Non-Proliferative Retinopathy & $6(37.5 \%)$ & $10(62.5 \%)$ & \\
\hline Moderate Non-Proliferative Retinopathy & $0(0.0 \%)$ & $9(100.0 \%)$ & \\
\hline Severe Non-Proliferative Retinopathy & $0(0.0 \%)$ & $2(100.0 \%)$ & \\
\hline Early Proliferative Retinopathy & $0(0.0 \%)$ & $1(100.0 \%)$ & \\
\hline Any Microvascular Complication (Present) & $22(44.9 \%)$ & $27(55.1 \%)$ & $0.216^{2}$ \\
\hline
\end{tabular}

, 1: t-test, 2: Fisher's Exact Test, 3: Chi-Squared Test, 4: Wilcoxon Test 
Table 13: Association between Mean Intimal Thickness ( $\mathrm{mm})$ and Parameters

\begin{tabular}{|c|c|c|}
\hline Parameters & Mean Intimal Thickness (mm) & p value \\
\hline Age (Years) & rho $=0.45$ & $<0.001^{1}$ \\
\hline Age & & $0.019^{2}$ \\
\hline$\leq 40$ Years & $0.40 \pm 0.16$ & \\
\hline 41-50 Years & $0.65 \pm 0.27$ & \\
\hline 51-60 Years & $0.73 \pm 0.25$ & \\
\hline $61-70$ Yearrs & $0.85 \pm 0.19$ & \\
\hline$>70$ Years & $0.95 \pm 0.07$ & \\
\hline Gender & & $0.150^{3}$ \\
\hline Male & $0.74 \pm 0.27$ & \\
\hline Female & $0.63 \pm 0.26$ & \\
\hline Duration of Diabetes (Years) & rho $=0.75$ & $<0.001^{1}$ \\
\hline Duration of Diabetes & & $<0.001^{2}$ \\
\hline Newly Diagnosed & $0.47 \pm 0.22$ & \\
\hline$\leq 5$ Years & $0.73 \pm 0.20$ & \\
\hline 6-10 Years & $0.87 \pm 0.15$ & \\
\hline$>10$ Years & $1.02 \pm 0.10$ & \\
\hline Alcohol Use & & $0.010^{3}$ \\
\hline Present & $0.84 \pm 0.27$ & \\
\hline Absent & $0.64 \pm 0.25$ & \\
\hline Smoking & & $0.078^{3}$ \\
\hline Present & $0.79 \pm 0.30$ & \\
\hline Absent & $0.66 \pm 0.25$ & \\
\hline BMI (Kg/m2) & rho $=0.2$ & $0.165^{1}$ \\
\hline FBS (mg/dl) & rho $=0.53$ & $<0.001^{1}$ \\
\hline PPBS (mg/dl) & rho $=0.43$ & $0.002^{1}$ \\
\hline HbA1c (\%) & rho $=0.58$ & $<0.001^{1}$ \\
\hline Diabetes Status & & $<0.001^{3}$ \\
\hline Diabetic & $0.81 \pm 0.21$ & \\
\hline Prediabetic & $0.44 \pm 0.21$ & \\
\hline Diabetes Control (HbA1c) & & $<0.001^{2}$ \\
\hline Prediabetes & $0.44 \pm 0.21$ & \\
\hline Good & $0.80 \pm \mathrm{NA}$ & \\
\hline Poor & $0.81 \pm 0.21$ & \\
\hline Urea $(\mathrm{mg} / \mathrm{dl})$ & rho $=0.23$ & $0.100^{1}$ \\
\hline Creatinine (mg/dl) & rho $=-0.01$ & $0.919^{1}$ \\
\hline 24 hrs Urine Protein (mg/day) & rho $=0.4$ & $0.003^{1}$ \\
\hline Urine Routine: Albumin & & $0.490^{2}$ \\
\hline Nil & $0.65 \pm 0.29$ & \\
\hline Trace & $0.68 \pm 0.27$ & \\
\hline $1+$ & $0.75 \pm 0.12$ & \\
\hline $2+$ & $0.80 \pm 0.30$ & \\
\hline $3+$ & $1.00 \pm \mathrm{NA}$ & \\
\hline Urine Routine: Sugar & & $0.016^{2}$ \\
\hline Nil & $0.48 \pm 0.18$ & \\
\hline Trace & $0.90 \pm \mathrm{NA}$ & \\
\hline $1+$ & $0.75 \pm 0.22$ & \\
\hline $2+$ & $0.66 \pm 0.26$ & \\
\hline $3+$ & $0.81 \pm 0.27$ & \\
\hline SGOT (IU/L) & rho $=0$ & $0.973^{1}$ \\
\hline SGPT (IU/L & rho $=-0.03$ & $0.832^{1}$ \\
\hline Hemoglobin (gm/dl) & rho $=-0.03$ & $0.821^{1}$ \\
\hline TLC (cells/cu.mm) & rho $=0.2$ & $0.167^{1}$ \\
\hline Platelet Count (thosuand/cu.mm) & rho $=-0.18$ & $0.200^{1}$ \\
\hline Diabetic Nephropathy & & $0.047^{2}$ \\
\hline Absent & $0.33 \pm 0.15$ & \\
\hline Microalbuminuria & $0.70 \pm 0.26$ & \\
\hline Macroalbuminuria & $0.84 \pm 0.18$ & \\
\hline Diabetic Neuropathy & & $<0.001^{2}$ \\
\hline No Neuropathic Changes & $0.57 \pm 0.26$ & \\
\hline Mild Neuropathic Changes & $0.81 \pm 0.12$ & \\
\hline Severe Neuropathic Changes & $1.01 \pm 0.09$ & \\
\hline Diabetic Retinopathy & & $<0.001^{2}$ \\
\hline No Retinopathy & $0.53 \pm 0.23$ & \\
\hline Mild Non-Proliferative Retinopathy & $0.75 \pm 0.23$ & \\
\hline Moderate Non-Proliferative Retinopathy & $0.92 \pm 0.11$ & \\
\hline Severe Non-Proliferative Retinopathy & $1.10 \pm 0.00$ & \\
\hline Early Proliferative Retinopathy & $0.80 \pm \mathrm{NA}$ & \\
\hline Any Microvascular Complication & & $0.037^{3}$ \\
\hline Present & $0.71 \pm 0.26$ & \\
\hline Absent & $0.25 \pm 0.07$ & \\
\hline
\end{tabular}

, 1: Spearman Correlation, 2: Kruskal Wallis Test, 3: Wilcoxon Test 


\section{Discussion}

Carotid intima media thickness (CIMT) is used commonly as a non-invasive test for the assessment of early occurrence of microvascular complications in type 2 diabetes mellitus. In this study majority of the subjects were in the age group of $4^{\text {th }}$ and $5^{\text {th }}$ decade was $35.3 \%$.Less percentage of subjects in the age group of more than 70 years was $3.9 \%$ and $9.8 \%$ of the participants in the age group of 40 Years. In this study $56.9 \%$ of the participants of gender were Male and $43.1 \%$ of the participants of female gender.

In this study $37.3 \%$ of the participants was newly diagnosed type 2 diabetes mellitus, $31.4 \%$ of the participants had duration of diabetes of 5 years, $19.6 \%$ of the participants had duration of diabetes of 6-10 years and the $11.8 \%$ of the participants had duration of diabetes of more than 10 years. According to this study, the mean (SD) of BMI (Kg/m2) was 22.63 (2.02), the median (IQR) of BMI (Kg/m2) was 23.00 (2.85) and the BMI $(\mathrm{Kg} / \mathrm{m} 2)$ ranged from 19 - 27.The mean (SD) of FBS (mg/dl) was 207.98 (86.18), the median (IQR) of FBS (mg/dl) was 200.00 (170.00)and the FBS (mg/dl) ranged from 99 - 367.The mean (SD) of PPBS (mg/dl) was 298.47 (110.73), the median (IQR) of PPBS (mg/dl) was 289.00 (209.00) and the PPBS $(\mathrm{mg} / \mathrm{dl})$ was ranged from 130 - 523.The mean (SD) of HbA1c (\%) was 9.13 (2.68) and the median (IQR) of HbA1c (\%) was 8.90 (5.70), HbAlc (\%) ranged from 5.7 - 13.In this study, $68.6 \%$ of the participants had diabetes status of type 2 Diabetes mellitus and $31.4 \%$ of the participants had diabetes status of Prediabetic. The mean (SD) of 24 hours Urine Protein (mg/day) was 131.63 (96.38), the median (IQR) of 24 hours Urine Protein (mg/day) was 101.00 (145.00) and the 24 hrs urine Protein ( $\mathrm{mg} /$ day) ranged from 25 $340.37 .3 \%$ of the participants had urine routine shows Albumin was nil, $39.2 \%$ of the participants had urine routine albumin was trace, $11.8 \%$ of the participants had urine routine shows albumin of $1+, 9.8 \%$ of the participants had urine routine shows albumin of $2+$ and $2.0 \%$ of the participants had urine routine of albumin of 3+.Gayathri et al ${ }^{1}$ was conducted a study result shows that CIMT was significantly higher in those type 2 diabetic patients who had atherosclerotic events than in those patients who had no atherosclerotic events. It was also found that waist hip ratio showed a significant positive correlation and independent association with CIMT emphasizing the emerging concept of central obesity.

In this study, $5.9 \%$ of the participants of type 2 diabetes mellitus had diabetic nephropathy was absent, $84.3 \%$ of the participants had diabetic nephropathy of microalbuminuria and the $9.8 \%$ of the participants had Diabetic nephropathy of macroalbuminuria. $58.8 \%$ of the participants had no neuropathic Changes, $27.5 \%$ of the participants had diabetic neuropathy of mild neuropathic changes and the $13.7 \%$ of the participants had severe neuropathic changes. $45.1 \%$ of the participants had no retinopathic changes, $31.4 \%$ of the participants had diabetic retinopathy ofmild non-proliferative retinopathy type. $17.6 \%$ of the participants had diabetic retinopathy of moderate non-Proliferative retinopathy, $3.9 \%$ of the participants had severe non-proliferative retinopathy and the $2.0 \%$ of the participants had early proliferative retinopathy.

From this study, association between mean intimal thickness with diabetic nephropathy in type 2 diabetes mellitus shows that $46.5 \%$ of the participants in the absent diabetic nephropathy group had mean intimal thickness of $>0.7 \mathrm{~mm}$. $53.5 \%$ of the participants in the group diabetic nephropathy of microalbuminuria had mean intimal thickness of $>0.7 \mathrm{~mm}$. There was no statistically significant difference between the various groups in terms of distribution of mean intimal thickness $\left(\mathrm{x}^{\wedge} 2=4.850, \mathrm{p}=0.124\right)$. Association between mean intimal thickness with diabetic neuropathy in type 2 diabetes mellitus shows that $70.0 \%$ of the participants in the group of no neuropathic changes had mean intimal thickness of $=0.7 \mathrm{~mm}, 21.4 \%$ of the participants in the group of no neuropathic changes had mean intimal thickness of $>0.7 \mathrm{~mm} .30 .0 \%$ of the 
participants in the group mild neuropathic changes had mean intimal thickness of $=0.7 \mathrm{~mm}$. $78.6 \%$ of the participants in the groupmild neuropathic changes had mean intimal thickness of $>0.7 \mathrm{~mm}$. There was a significant difference between the various groups in terms of distribution of mean intimal thickness $\left(x^{\wedge} 2=\right.$ 16.251, $\mathrm{p}=<0.001)$. Association between mean intimal thickness with diabetic retinopathy in type 2 diabetes mellitus shows that $78.3 \%$ of the participants in the group no retinopathy had mean intimal thickness of $=0.7 \mathrm{~mm}, 37.5 \%$ of the participants in the group no retinopathy had mean intimal thickness of $>0.7 \mathrm{~mm} .21 .7 \%$ of the participants in the group mild non-proliferative retinopathy had mean intimal thickness of $=0.7$ $\mathrm{mm} .62 .5 \%$ of the participants in the group mild non-proliferative retinopathy had mean intimal thickness of $>0.7 \mathrm{~mm}$. There was a significant difference between the various groups in terms of distribution of mean intimal thickness $\left(x^{\wedge} 2=\right.$ 20.241, $\mathrm{p}=<0.001)$. Summary of this study results all was shown in Table 11,12,13.

\section{Limitations}

Less statistical power due to small study population and single center study, small duration of study.

\section{Conclusion}

From this study, result shows that association of mean carotid intima media thickness (CIMT) was statistically significant with diabetic neuropathy and diabetic retinopathy but statistically not significant with diabetic nephropathy changes. So finally concluded that Carotid intima media thickness (CIMT) is commonly as a non-invasive test for the assessment of early occurrence of diabetic neuropathy and diabetic retinopathy changes in type 2 diabetes mellitus patients. Also correlated CIMT with various parameters of age, HbA1c, BMI, duration of type 2 diabetes mellitus it shows statistically significant $\mathrm{P}$ value.

\section{References}

1. Gayathri R, Chandni R, Udayabhaskaran $\mathrm{V}$. Carotid artery intima media thickness in relation with atherosclerotic risk factors in patients with type 2 diabetes mellitus. J Assoc Physicians India. 2012 Sep;60:20-4.

2. Ichinohasama $\mathrm{K}$, Kunikata $\mathrm{H}$, Ito $\mathrm{A}$, Yasuda M, Sawada S, Kondo K, Satake C, Katagiri H, Nakazawa T. The Relationship between Carotid Intima-Media Thickness and Ocular Circulation in Type-2 Diabetes. Journal of ophthalmology. 2019;2019.

3. Bhinder HP, Kamble TK. The study of carotid intima-media thickness in prediabetes and its correlation with cardiovascular risk factors. Journal of Datta Meghe Institute of Medical Sciences University. 2018 Apr 1;13(2):79.

4. Gayathri R, Chandni R, Udayabhaskaran V. Carotid artery intima media thickness in relation with atherosclerotic risk factors in patients with type 2 diabetes mellitus. J Assoc Physicians India. 2012 Sep;60:20-4.

5. Olt S, Şirik M, Baykan AH, Çeliker M. The relationship between HbA1c and carotid intima-media thickness in type 2 diabetic patients. Pan African Medical Journal. 2016;23(1).

6. Brohall G, Oden A, Fagerberg B. Carotid artery intima-media thickness in patients with Type 2 diabetes mellitus and impaired glucose tolerance: a systematic review. Diabetic medicine. 2006 Jun;23(6):609-16.

7. Taniwaki H, Kawagishi T, Emoto M, Shoji T, Kanda H, Maekawa K, Nishizawa Y, Morii H. Correlation between the intimamedia thickness of the carotid artery and aortic pulse-wave velocity in patients with type 2 diabetes. Vessel wall properties in type 2 diabetes. Diabetes Care. 1999 Nov 1;22(11):1851-7. 